\title{
A case of painless exercise-induced gross hematuria in a 9-year-old boy: Questions
}

\author{
Anna Zisi ${ }^{1} \cdot$ Chrysoula Kosmeri $^{1} \cdot$ Ioanna Siatara $^{1} \cdot$ Anastasia Giantsouli $^{2} \cdot$ Vasileios Xydis $^{2} \cdot$ Ekaterini Siomou $^{1}$ (D)
}

Received: 6 September 2020 / Accepted: 29 September 2020 / Published online: 22 October 2020

(C) IPNA 2020

Keywords Child · Gross hematuria $\cdot$ Exercise-induced $\cdot$ Painless

\section{Case summary}

A previously healthy 9-year-old boy was admitted to the Pediatric Nephrology Department for investigation of recurrent painless episodes of red coloration of the urine over the previous 15 days. He reported 3 episodes of passage of red colored urine, occurring immediately after exercise and lasting for 2 or 3 urinations. No fever or other symptoms were reported. The family history was negative for kidney disease and hematological disorders, apart from nephrolithiasis in the father.

On admission, the boy was hemodynamically stable. His blood pressure was 116/78 $\mathrm{mmHg}$ (95th percentile for his height $-119 / 80 \mathrm{mmHg}$ ), and physical examination revealed no pathological signs. His body mass index (BMI) was 14.6.

The hemoglobin level, white blood cell and platelet counts, levels of serum electrolytes and creatinine, and liver function tests were all within the normal range. The fractions of serum complement $\mathrm{C} 3$ and $\mathrm{C} 4$ were in the lower normal range $(\mathrm{C} 3$ $84 \mathrm{mg} / \mathrm{dl}$, normal range $83-177 \mathrm{mg} / \mathrm{dl}$, and C4 $15 \mathrm{mg} / \mathrm{dl}$, normal range $15-45 \mathrm{mg} / \mathrm{dl}$ ). The antistreptolysin $\mathrm{O}$ antibodies (ASTO) titer was $613 \mathrm{IU} / \mathrm{ml}$ (normal < $200 \mathrm{IU} / \mathrm{ml}$ ), and throat swab culture was positive for group A $\beta$-hemolytic Streptococcus, although no clinical symptoms of streptococcal tonsillitis or skin infection were reported.

Urinalysis revealed density 1.015, $\mathrm{pH} 6$, negative albumin, hemoglobin +++, and erythrocytes $80-100$ cells/hpf. Twenty-

The answers to these questions can be found at https://doi.org/10.1007/ s00467-020-04807-w.

Ekaterini Siomou

eksiomou@yahoo.gr

1 Department of Pediatrics/Pediatric Nephrology, University Hospital of Ioannina, Stavros Niarchos Avenue, 45500 Ioannina, Greece

2 Department of Radiology, University Hospital of Ioannina, Ioannina, Greece four-hour urine collection revealed calcium excretion $5 \mathrm{mg} / \mathrm{kg} / \mathrm{d}$ and total protein excretion $84 \mathrm{mg} / \mathrm{m}^{2} / \mathrm{d}$, and urine culture was negative. Urinary tract ultrasound was normal, and abdominal X-ray showed no calculi.

He was hospitalized for 4 days, during which time no further episode of macroscopic hematuria occurred. Urinalysis on discharge was normal: density $1.016, \mathrm{pH} 6$, albumin negative, hemoglobin negative, and erythrocytes $0-2$ cells/hpf.

\section{Questions}

1. Which diseases should be considered in the differential diagnosis of this patient?

2. What is the most likely diagnosis?

3. What investigations would you perform to reach a definitive diagnosis?

4. How should this patient be treated?

Data availability Not applicable.

\section{Compliance with ethical standards}

Conflict of interest The authors declare that they have no conflict of interest.

Ethics approval Not applicable.

Consent to participate Not applicable.

Consent for publication Not applicable.

Code availability Not applicable.

Publisher's note Springer Nature remains neutral with regard to jurisdictional claims in published maps and institutional affiliations. 